Article

\title{
Isolation, Characterization, and Agent-Based Modeling of Mesenchymal Stem Cells in a Bio-construct for Myocardial Regeneration Scaffold Design $^{+}$
}

\author{
Diana Victoria Ramírez López ${ }^{1, *}$, María Isabel Melo Escobar ${ }^{1}{ }^{*}$, Carlos A. Peña-Reyes ${ }^{2}$ D, \\ Álvaro J. Rojas Arciniegas ${ }^{1}$ (D) and Paola Andrea Neuta Arciniegas ${ }^{1}$ \\ 1 College of Engineering, Universidad Autónoma de Occidente, Calle 25 115-85, Cali 760030, Colombia; \\ ajrojas@uao.edu.co (A.J.R.A.); paneuta@uao.edu.co (P.A.N.A.) \\ 2 School of Business and Engineering Vaud (HEIG-VD), University of Applied Sciences Western of \\ Switzerland (HES-SO), Route de Cheseaux 1, CH-1400 Yverdon-les-Bains, Switzerland; \\ carlos.pena@heig-vd.ch \\ * Correspondence: ramirezvicky4@gmail.com (D.V.R.L.); meloescobarov@gmail.com (M.I.M.E.); \\ Tel.: +57-311-648-9357 (D.V.R.L.); +57-310-865-9150 (M.I.M.E.) \\ + This paper is an extended version of our paper published in 2018 IEEE International Conference on \\ Bioinformatics and Biomedicine (BIBM), Madrid, Spain, 3-6 December 2018, doi:10.1109/BIBM.2018.8621314.
}

Received: 28 March 2019; Accepted: 16 May 2019; Published: 19 May 2019

\begin{abstract}
Regenerative medicine involves methods to control and modify normal tissue repair processes. Polymer and cell constructs are under research to create tissue that replaces the affected area in cardiac tissue after myocardial infarction (MI). The aim of the present study is to evaluate the behavior of differentiated and undifferentiated mesenchymal stem cells (MSCs) in vitro and in silico and to compare the results that both offer when it comes to the design process of biodevices for the treatment of infarcted myocardium in biomodels. To assess in vitro behavior, MSCs are isolated from rat bone marrow and seeded undifferentiated and differentiated in multiple scaffolds of a gelled biomaterial. Subsequently, cell behavior is evaluated by trypan blue and fluorescence microscopy, which showed that the cells presented high viability and low cell migration in the biomaterial. An agent-based model intended to reproduce as closely as possible the behavior of individual MSCs by simulating cellular-level processes was developed, where the in vitro results are used to identify parameters in the agent-based model that is developed, and which simulates cellular-level processes: Apoptosis, differentiation, proliferation, and migration. Thanks to the results obtained, suggestions for good results in the design and fabrication of the proposed scaffolds and how an agent-based model can be helpful for testing hypothesis are presented in the discussion. It is concluded that assessment of cell behavior through the observation of viability, proliferation, migration, inflammation reduction, and spatial composition in vitro and in silico, represents an appropriate strategy for scaffold engineering.
\end{abstract}

Keywords: agent-based modeling; biological system modeling; cell migration; cell viability; computational modeling; myocardium; myocardial infarction; scaffold; stem cells; tissue engineering

\section{Introduction}

Cardiovascular diseases are a public health problem that represents $30 \%$ of the world mortality. MI is one of the five main expressions of coronary disease, which implies an obstruction in the blood flow due to the presence of plaques in the coronary arteries that causes myocardial cell necrosis due to 
sustained ischemia. The repercussions vary, causing rupture of the interventricular septum, formation of a pseudoaneurysm, rupture of the free wall, among other complications that can result in death [1].

The failure of current treatments to restore completely the functional myocardium [1] has led to a search for new strategies in tissue engineering through cell therapy by stimulating endogenous regenerative mechanisms of the body. Particularly, the interaction of a cell source and a biopolymeric material, known as a scaffold, is considered a compelling candidate in tissue regeneration to optimize cell development in the injured area [2]. Scaffolds should exhibit very precise properties such as elasticity matching the myocardium, host cell integration and vascularization, mechanical stability, and non-immunogenicity to support tissue function and regeneration [3].

The first and most significant step toward success in tissue regeneration is the ability to find a viable cell source [4], thus, isolation and cell culture are critical stages for scaffold construction. Moreover, cell survival and migration are important parameters that determine the outcome of a successful regeneration platform, and for this reason an in vitro analysis is performed in order to observe, at some level, the behavior of the cells that could be used in a scaffold as a regenerative treatment and use the obtained results to condition some characteristics of a computational model, which can be found in the GitHub repository linked as Supplementary Material.

Computational modeling aims at replicating the behavior of the system it parallels, and to do so based on actual, known properties of the system components. Regarding cell behavior, this technique stands as an important complement to experimental and theoretical studies, and provides insights into the complex interactions that entail engineered scaffolds [5]. One example of computational techniques for model stem cell behavior can be found in the work of Briers et al. [6], where they develop a parametric classification method and use particle swarm optimization to maximize the occurrence of morphogenic patterns (spheres), known as embryoid bodies (EB), used to study the 3D cell differentiation. Tanaka et al. [7] also studied the differentiation of MSCs and the patterns they form using a computational tool, in this case they develop an image processing software able to classify two different types of cell "clusters" that would form in a culture, where one would be conformed by osteogenic cells and the other by adipogenic cells. An earlier work by Inverno and Saunders [8] shows an agent-based approach where a comparison between cellular-automata and agent-based models leads them to conclude that the latter is better for modeling cell behavior with biological plausibility, mainly because it allows the inclusion of properties of the cellular microenvironment by simple behavioral rules that mask the complexity of the interactions between many components.

Our study aims at identifying the behavior of rat Mesenchymal Stem Cells (MSCs) in a collagen scaffold, regarding viability and migration, to generate an agent-based model able to give information about the viability of the cells after a certain period of time, the differentiation of MSCs, and how the cells might arrange over the myocardial tissue. Hence, a better understanding and prediction of this biological system would contribute to therapeutic strategies by providing information about relevant variables or design modifications that could result in enhanced scaffold properties for the myocardial repair treatment proposed.

\section{Methods}

\subsection{In Vitro Experiments}

This study was developed as part of the project "Design and construction of a scaffold from a biomaterial that serves as support for mesenchymal stem cells (MSC) of pig bone marrow, for its potential use in the regeneration of the infarcted myocardium of a biomodel" of the Tissue Engineering Research Seeding Group and the Additive Manufacturing Research Seeding Group of Autónoma de Occidente University (Colombia). The work is likewise, part of the project "Research and Production of Tissues, Organs and Biodevices for use in Regenerative Medicine, Cali, Valle del Cauca", which has the endorsement of the Animal Research Ethics Committee of the Universidad del Valle. 
Wistar rats between 1 and 3 months of age, bred at the bioterium of Universidad del Valle were used, from which the hindlimbs were taken. The selected cell lineages were MSCs, cardiomyocytes and endothelial, since they are the most relevant types in angiogenesis of myocardial tissue [9].

\subsubsection{MSCs Isolation}

The rats were overdosed by isoflurane inhalation and disinfected for $10 \mathrm{~min}$ in iodine solution. Next, the hind limbs bones were extracted, cleaned, and placed in a $15 \mathrm{~mL}$ centrifuge tube with DMEM (CAT \# SLM-021-B, EmbryoMax, Sigma-Aldrich, St. Louis, MI, USA).

In the laminar flow cabinet, the epiphyses were cut and the bone marrow was washed into 15 $\mathrm{mL}$ centrifuge tubes, which were taken to the centrifuge for $10 \mathrm{~min}$ at $2500 \mathrm{rpm}$. Finally, the pellet of each tube was resuspended in $5 \mathrm{ml}$ of culture medium containing DMEM, Fetal Bovine Serum (SFB, Millipore TMS-013-B, MilliporeSigma, Burlington, MA, USA) at 10\% and Penicillin/Streptomycin (CAT \# 17-602E, Lonza, Basel, Switzerland) at 1\%; after this, the content was transferred to a T-25 culture flask.

\subsubsection{Cell Culture and Differentiation}

Each bottle was placed under incubation conditions of $37^{\circ} \mathrm{C}$ and $5 \% \mathrm{CO}_{2}$ with a change of fresh medium every $72 \mathrm{~h}$ (Medium of mesenchymal stem cells MSCGM-CD BulletKit, Lonza). When cells reached $90 \%$ confluence, subculture was performed. Cells were detached with $0.25 \%$ enzymatic treatment of trypsin (BE17-160E, Lonza) in the incubator with $5 \% \mathrm{CO}_{2}$, for $5 \mathrm{~min}$. Also, $10 \% \mathrm{SFB}$ was added to neutralize the trypsin and taken to the centrifuge for $10 \mathrm{~min}$ at $2500 \mathrm{rpm}$. Once the supernatant was discarded, the cells were resuspended and disrupted by successive pipetting to re-suspend into new bottles. At the time when P1 reached 90\% confluence, the cells were disrupted, collected by centrifugation and successively subcultured until the sixth passage (P6). All flasks were supervised on the inverted microscope.

In the fourth passage (P4) the differentiation to cardiomyocytes and endothelial cells was initiated with Milipore Cardiomyocyte Differentiation Medium and EGMTM-2 Endothelial Cell Growth Medium. Differentiation medium was changed every 2 or 3 days. This process was continued for 12 or 15 days, time in which the cells reach differentiation.

\subsubsection{Cell Seeding}

Bases of $10 \mathrm{~mm} \times 10 \mathrm{~mm}$ each were made in Polyethylene Terephthalate Glycol with Carbon Fiber (PETG CF), printed by additive manufacturing on a slide. Each base designed for 2 scaffolds was sterilized inside a petri dish in the autoclave. Scaffolds were made in 2 groups for cell viability and 2 groups for cell migration. For the evaluation of cell survival, a homogenous cell distribution was poured in the base, but 2 different cell concentrations were examined. On the other hand, to study the cells migration, one group was seeded in homogeneous distribution and the other was arranged crosswise, to evaluate its influence on the cell types' growth (Table 1).

Table 1. Cell seeding methodology.

\begin{tabular}{ccccc}
\hline & Group 1 & Group 2 & Group 3 & Group 4 \\
\hline Test & Cell Viability & \multicolumn{2}{c}{ Cell migration } \\
Cell distribution & Homogeneous & Homogeneous & Crosswise \\
Scaffolds number & \multicolumn{2}{c}{24} & \multicolumn{2}{c}{12} \\
Cell concentration & 750 cells $/ \mu \mathrm{L}$ & 5000 cells $/ \mu \mathrm{L}$ & 2250 cells $/ \mu \mathrm{L}$ \\
\hline
\end{tabular}

\subsubsection{Cell Viability Scaffolds}

Group 1 and 2 scaffolds, intended for the evaluation of cell survival in two different concentrations (750 cells $/ \mu \mathrm{L}$ and 5000 cells $/ \mu \mathrm{L}$ ), were manufactured by detaching the corresponding content from the 
culture flasks with $0.25 \%$ trypsin in the incubator with $5 \% \mathrm{CO}_{2}$, for $5 \mathrm{~min}$ to centrifuge at $2500 \mathrm{rpm}$ for $10 \mathrm{~min}$. Each cell type was resuspended in rat tail type I collagen (EMD Millipore 08-115) separately and according to the cell concentration of the group. Then, $100 \mu \mathrm{L}$ of each cell suspension was taken to pour a total of $300 \mu \mathrm{L}$ into the PETG bases printed in 3D. Finally, each scaffold was gelled inside of an ammonium hydroxide vapor chamber (20-30\% J.T. Baker 9721-01, Avantor, Radnor, PA, USA). For this, sterile cotton is soaked in the ammonium hydroxide and placed next to the base in a $150 \mathrm{~mm}$ Petri dish sealed with parafilm for $10 \mathrm{~min}$. Then, the gelled scaffolds were washed with HBSS. A set of 2 PETG bases was deposited with 4 scaffolds per Petri dish adding sufficient DMEM culture medium until they were immersed in it. This culture was maintained in incubation at $37^{\circ} \mathrm{C}$ and $5 \% \mathrm{CO}_{2}$ for certain times. Its development was supervised by microscopy, with permanent change of medium every $3-4$ days.

\subsubsection{Fluorescent Labeling}

In order to manufacture the groups 3 and 4 scaffolds for the cell migration test, the contents of 2 culture flasks per cell type were detached by the aforementioned method. Each cell type was marked by staining with fluorochromes (DiI, DiO, and DAPI) at the concentrations shown in the following table (Table 2).

Table 2. Fluorophores used for cell labeling.

\begin{tabular}{cccc}
\hline & MSCs & Cardiomyocytes & Endothelial Cells \\
\hline Fluorophore & Dil & DAPI & DiO \\
Cell distribution & $5 \mu \mathrm{L} / 10 \mathrm{~mL}$ & $2 \mu \mathrm{L} / 10 \mathrm{~mL}$ & $9 \mu \mathrm{L} / 10 \mathrm{~mL}$ \\
\hline
\end{tabular}

\subsubsection{Cell Migration Scaffolds}

For both groups 3 and 4, the cells were resuspended in collagen and $100 \mu \mathrm{L}$ of each cell type was taken to the PETG bases for a total of $300 \mu \mathrm{L}$ per scaffold. However, for group 3 endothelial cells were distributed crosswise to evaluate variations in migration. Finally, they were gelled in an ammonium hydroxide vapor chamber, as mentioned above, and they were cultivated in the same way as the scaffolds manufactured for viability.

\subsubsection{Cell Viability Assay}

Cell viability was detected through trypan blue, using the Neubauer chamber and direct microscopic counting. Prior to the test, each scaffold was digested in a $0.2 \%$ HBSS solution with type V collagenase (SIGMA ${ }^{\circledR} \mathrm{C}-9263$ ) at $1 \mathrm{~g} / \mathrm{mL}$ for $25 \mathrm{~min}$ at $37^{\circ} \mathrm{C}$, then centrifuged at $2500 \mathrm{rpm}$ for $10 \mathrm{~min}$ and the pellets were resuspended in $200 \mu \mathrm{L}$ of HBSS. Cell counting was performed according to the standard protocol. To corroborate this test, stained cells were taken to a slide and the cells were counted in at least 10 fields of vision, to calculate the average number of live and dead cells per field.

\subsubsection{Cell Migration Assay}

The migration scaffolds were analyzed by fluorescence microscopy, capturing images of reference points in both the scaffold of homogeneous distribution and the crosswise distribution. The capture was made every $192 \mathrm{~h}$ for 4 weeks through the software Leica ${ }^{\circledR}$ LAS EZ (Leica, Buffalo Grove, IL, USA). The images were analyzed by means of the ImageJ digital image processing program.

\subsubsection{Statistical Analysis}

Each experiment was performed three times. Information corresponding to the percentages of cell viability was analyzed using the Hypothesis Test for proportions $(\alpha=0.05)$. The distances obtained in the migration test were analyzed through the coefficient of variation. 


\subsection{In Silico Approach: Agent-Based Modeling}

The cell population of the scaffold can be modeled as a system of interacting and reacting agents, where the reactions at micro level cause emergent behaviors at the system level. This is because agents can be modified through the addition of attributes that correspond to biological properties of cells and the interactions between large amounts of agents can be modeled according to what is known about the different processes that occur at a cellular level [10]. We use Netlogo, a free, open-source software that provides a programmable modeling environment for the simulation of natural and social phenomena [11]. Thanks to its flexibility, the language is used to implement and simulate two types of agents: Cells and substrate (or environment). Thanks to this design decision, both kinds of simulated entities are able to react/interact with each other and exhibit interesting behavior.

The model developed might be divided in 4 sections. First the agents and their attributes are defined. After this, the model must be initialized with a set of desired initial conditions; a method is assigned to this, which we called 'Setup', and should only be called for initialization. In third place, the actions that we want the agents to perform with each iteration are defined in a new method, which we call ' $G o^{\prime}$, and is called repeatedly during the simulation.

\subsubsection{Agents' Attributes}

There are two types of agents. There are those that represent the heart tissue where the scaffold (made of cells and collagen) is placed, which are squared, conform a grid and have a fixed position. These agents can represent either cardiac tissue or blood vessels and their attributes are "damage" and "inflammation". "Damage" is a boolean attribute which value is 1 for tissue areas that have died due to ischemia and "inflammation" is a real value between 0 and 1 and represents the reaction of the myocardial tissue after an infarction.

The second type of agents that represent cells in the scaffold can be one of three possible types (cell types). Those representing MSCs have 5 attributes, which are linked to the differentiation capability of this cell type [12]: "Cardiomyocyte differentiation probability", "endothelial differentiation probability", "differentiation time counter", "duration of the differentiation process" and "following cell type". Likewise, the agents that represent cardiomyocytes and endothelial cells have attributes related to the interactions with MSCs and the microenvironment that we want to model: "Probability of dying by apoptosis" and "influence over the differentiation decision".

\subsection{2. 'Setup' Method}

All the initialization values need to be established to set up the model. In the 'Setup' method, cell agents are created over a grid of tissue agents and a cell type and tissue type are assigned to each of them respectively, see Figure 1. Tissue agents that will represent blood vessels are chosen based on a pattern that is copied from an image. The initial number of cells that are created in this method must be determined to initialize the model, as well as the pattern in which the endothelial cells are distributed, which can be loaded from a black and white image. The number of tissue agents is determined by the size of the area that we want to simulate.
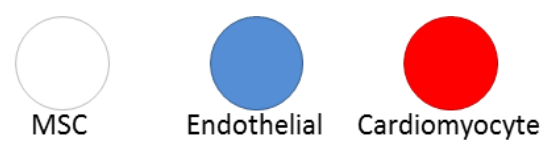

Figure 1. Different cell types are identified depending on their color. White is assigned to MSCs, blue to endothelial cells and red to cardiomyocytes.

The scaffold contains an arrangement of layered cells as one can be on top of another. Thus, in the model, a tissue agent (position) can be occupied by a number of cells that is set when it is initialized. A neighborhood of radius three, measured in cells perpendicular to the $\mathrm{x}-, \mathrm{y}$ - or $\mathrm{z}$-axis, is defined for MSCs, meaning that, e.g., if the model is set to have a maximum of 3 cells in each position, a maximum 
of 86 cell agents could conform the neighborhood ("neighborhood size" = 86) (Figure 2). The latter needs to be defined in order to identify the agents that will affect an MSC's fate during the simulation.

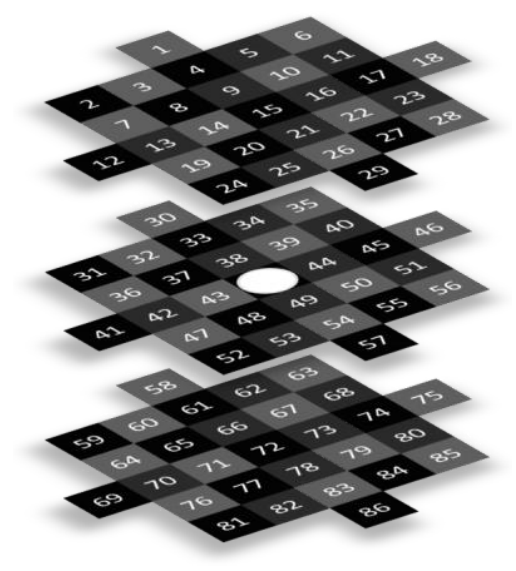

Figure 2. Example of a 3-layer neighborhood of an MSC.

Another value set for initialization is the size of the scar ("scar-size"), where it is possible to choose the percentage of the width ("max-pxcor") of the simulated area that will be the radius of the scar, since it is simulated as a circular area:

$$
\text { radius }=\text { max-pxcor } \times(\text { scar-size } / 100)
$$

the "inflammation" attribute of the tissue agents within that radius is set to 1 because MI is associated with an inflammatory reaction $[10,11]$.

Finally, the values of the maximum and minimum probability that an MSC will have of differentiating to one of the other cell types if all of these were occupied by cells of one type only are set (Figure 3).

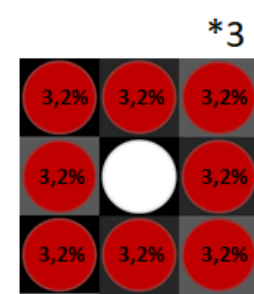

Max. probability of differentiating into cardiomyocyte $=80 \%$

*3

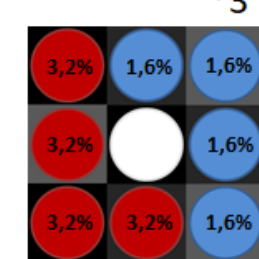

Probability of differentiating into cardiomyocyte $=40 \%$

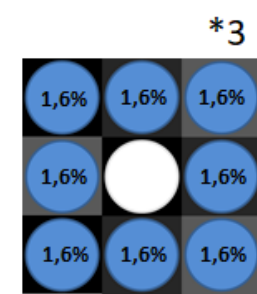

Max. probability of differentiating into endothelial $=40 \%$

Figure 3. Graphic description of the effect of the values of maximum cardiomyocyte/endothelial differentiation probability that are needed for initialization ("max-pc-cardio", "max-pc-endo"). In this example the values should be 0.8 for cardiomyocytes and 0.4 for endothelial cells, these numbers are divided by the number of cells that could be in the neighborhood of the MSC (which in this case would be a Moore neighborhood with maximum 3 cells per position) and become the influence over the MSCs' differentiation decision of each cardiomyocyte and endothelial cell.

\subsection{3. 'Go' Method}

This method is in charge of calling other methods that code the actions of the agents; it executes all the methods once and then restarts, meaning that it runs repeatedly, and each loop represents the simulation of one day for all the agents. The cells go through apoptosis, differentiation, proliferation and migration processes each day, where each of them is described in a separate method, and some values 
are adjusted according to the resulting behavior after the agents undergo the processes mentioned above, mainly based on the evolution of the inflammation thanks to the action of the MSCs.

\subsubsection{Cellular Interactions Put in Methods}

MI is associated with an inflammatory reaction $[13,14]$ and since the use of MSCs has resulted compelling for tissue repairing, research focused on the potential release of bioactive factors by MSCs has enabled the confirmation of their immunomodulatory properties [15]. These properties are considered in the model through the modification of the variable "inflammation percentage" of each agent that represents cardiac tissue. An MSC exerts its anti-inflammatory effect by reducing the "inflammation" value of the tissue agents that surround it inside a radius six by 0.01 for each simulated day, 0 being the minimum "inflammation" value possible.

After a MI, an apoptosis of cardiomyocytes occurs [13,16], and this is affected by inflammation [14], which is caused by a cascade of the pro-inflammatory cytokine TNF- $\alpha$, which interaction with MSCs' function can result in protection against myocardial ischemia [17]. This process is simulated for each cardiomyocyte and endothelial cell by generating a random number between 0 and 1 which is compared to the value of "probability of dying by apoptosis" that is initialized in 0.01 for each cell, representing a daily $1 \%$ probability of dying through programmed death according to the high viability results obtained from the in vitro observations, which is updated daily according to the inflammation value of the tissue agent in the position where the cell is. If the random number is greater than or equal to the cell's "probability of dying by apoptosis", the cell dies, but if it is smaller it lives until the next day, when the same evaluation would be performed.

As it was mentioned before, one of the most important characteristics of MSCs is their ability to differentiate into other cell types. In the model, a cell first decides which will be her following cell type before beginning the differentiation process. The decision is made based on the number of cardiomyocytes and endothelial cells in the neighborhood of the MSC. The sums of the percentages of each cell type, explained in Figure 3, are compared to one random number and the MSC decides if it will differentiate into one of the two possible cell types or remain undifferentiated:

$$
\begin{gathered}
\mathrm{P}_{\text {cardiomyocyte }}=\sum \mathrm{P}_{\text {neighboring cardiomyocytes }} \\
\mathrm{P}_{\text {endothelial }}=\sum \mathrm{P}_{\text {neighboring endothelials }} \\
\text { Cell type }=\left\{\begin{array}{l}
\text { If } 0<\text { rand }<\mathrm{P}_{\text {cardio, }} \text { Cardiomyocyte } \\
\text { If } \mathrm{P}_{\text {cardio }}<\text { rand }<\mathrm{P}_{\text {endo }} \text {, Endothelial } \\
\text { If } \mathrm{P}_{\text {endo }}<\text { rand }<1, \text { No differentiation }
\end{array}\right.
\end{gathered}
$$

The differentiation of a stem cell is not instantaneous. Stem cells go through various stages of differentiation and there is no determination of the number of stages connecting stem cells and fully differentiated cells, let alone how fast cells go through them [18]. Thus, differentiation time is modeled as a normal distribution with mean $\mu=16$ and standard deviation $\sigma=3$, which represents the time that the rat cells used for the in vitro observation took to differentiate. A random number from this distribution is created for each cell that has decided to differentiate and it will determine the number of days in which a cell will change its type.

After the agents have gone through the differentiation method, the value of "influence over the differentiation decision" ( $\%$ cardio', '\%endo') that every cell has is changed considering the reduction of inflammation that could have happened in the underlying tissue. This means that a MSC would be more prone to differentiation once the inflammation starts to reduce thanks to its own effect over the damaged tissue, which is described by the following equation, where we used 86 as the maximum 
number of cells that would occupy the neighborhood of an MSC ("neighborhood size") in the example described for Figure 2:

$$
\begin{aligned}
& \%_{\text {cardio }}=\frac{\text { max-pc-cardio }}{\text { neighborhood size }} \times(1-\text { inflammation }) \\
& \%_{\text {endo }}=\frac{\text { max-pc-endo }}{\text { neighborhood size }} \times(1-\text { inflammation })
\end{aligned}
$$

The last equation models an indirect linear behavior for the described values, where the maximum value that a cell could take is given by the values of "max-px-cardio" and "max-pc-endo" used to initialize the model, which represents the maximum cardiomyocyte/endothelial differentiation probability as it was explained in Figure 3.

One of the most important characteristics of stem cells is their proliferative capacity [19]. Likewise, it has been demonstrated that they promote angiogenesis by either differentiating into endothelial cells or promoting their proliferation [18]. MSCs proliferation is modeled by defining a division probability, which is set as $10 \%$, meaning that only a $10 \%$ of the total amount of MSCs on the affected area, chosen randomly for each simulated day, will have the chance to proliferate. A cell from this $10 \%$ will divide depending on the inflammation of the tissue under it and whether or not there is free space in its 4-connected Moore neighborhood, because the adjacent positions are more likely to be occupied through mitosis [20]. The proliferation of endothelial cells is modeled on a similar way, except for the fact that only $2 \%$ of these cells would have the chance to divide as it is considered that due to the need for a repair the MSCs will be much more likely to proliferate. The proliferation of cardiomyocytes in the damaged area is activated by the presence of MSCs in a radius 3, because it has been proved that they activate the proliferation of myocytes in the infarcted myocardium [21].

Finally, as it has been proved that cells perform random movements and walks on surfaces and it is considered that cellular automata and particle models are a promising method to simulate cell migration [20], this is also performed by the cells in the model. MSCs and cardiomyocytes change their position each simulated day by moving a maximum of 5 positions in a random direction [20], always checking if there is space for one more cell in the following position. Endothelial cells are known to promote angiogenesis in the damaged tissue [18], thus their movement is conditioned by their proximity to the existent blood vessels, represented by tissue agents; if they are not connected to other endothelial cells, they will move a maximum of 6 positions per day towards the closest blood vessel tissue agent, which represents the ability they have of connecting new tissue to the circulatory system in order to bring oxygen to the cells.

\section{Results}

\subsection{MSCs Isolation From Rat Bone Marrow}

To avoid contamination, a bone marrow stem cell extraction protocol was performed, adapted to the facility in which it was executed, and modified from possible errors and recommendations in already established protocols. The bone marrow was washed without filtering to keep the MSCs in the initial niche with minimal alterations, and the samples were processed in less than $30 \mathrm{~min}$ after the sacrifice of the animal and all soft tissue was removed to prevent contamination. It is important to keep the bones in cold DMEM from the moment they are extracted until washing to ensure high cell viability. Also, 47 T-75 culture flasks were cultured to provide the required cell concentrations for the viability and cell migration tests, with a minimum number of 3 repetitions.

\subsection{MSCs Culture and Differentiation}

For passages 1-3, high confluence (80-90\%) was reached within 5-6 days. From passages 4 (P4) to P6, a high confluence was observed after $96 \mathrm{~h}$ of culture (Figure 4 ). In the first $24 \mathrm{~h}$, non-adherent cells are detected, identified by their rounded morphology and more flattened cell bodies in the adhesion 
process to the substrate. Within $48 \mathrm{~h}$, the extension of the cytoskeleton during focal adhesion formation is evident, to finally generate a cell monolayer.

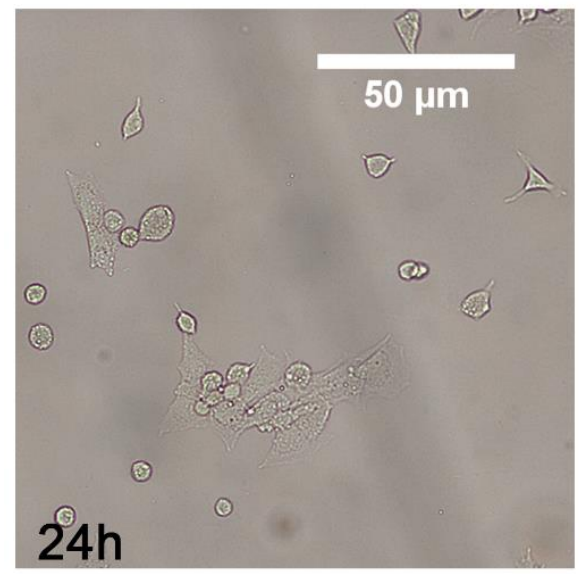

(a)

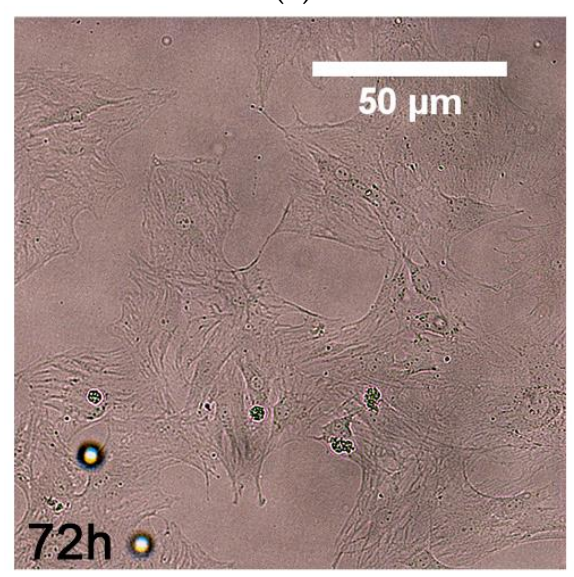

(c)

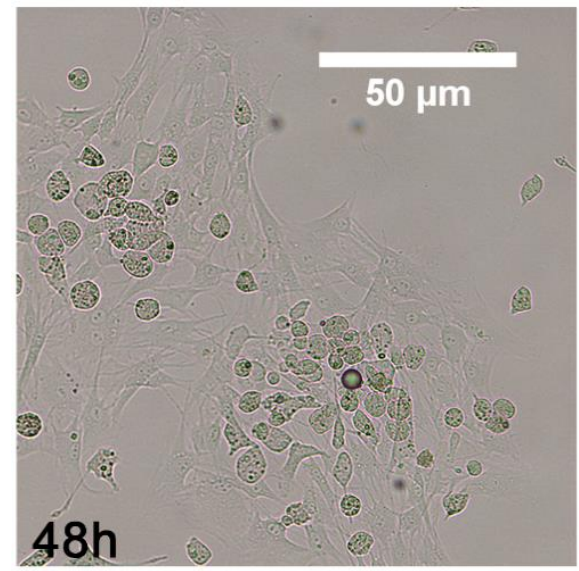

(b)

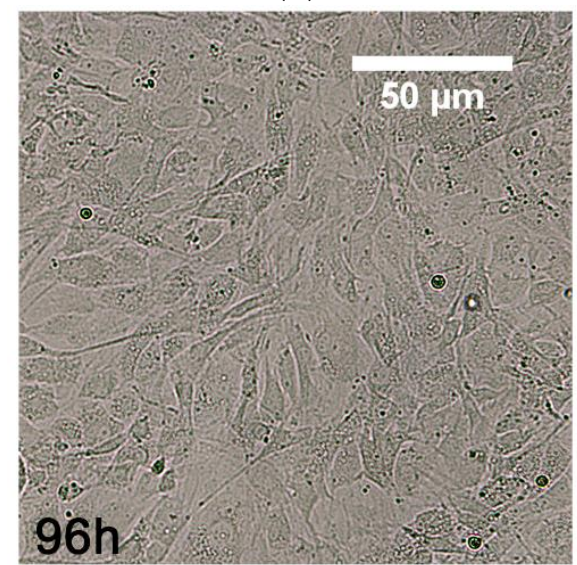

(d)

Figure 4. MSC proliferation within 96 h. (a) Initial phase of focal adhesion. Rounded cell bodies start to gather and adhere to the flask surface. (b) Cells initiate the migration cycle by polarizing and extending protrusions of the cell membrane after $48 \mathrm{~h}$. (c) Space between cells diminishes with more stable adhesion and cell growth. (d) Cell monolayer of confluence above $90 \%$ after $96 \mathrm{~h}$.

MSCs isolation from 4 weeks old rats resulted in successful cell culture which showed the morphology and development of a cell monolayer without contamination, unlike previous cultures where the rats were 6-8 weeks old and a healthy cell morphology could not be appreciated.

Microscopy assessment of MSCs allowed the observation of heterogeneous cell populations, elongated, rounded, and flattened cells were observed; the clearance of the non-adherent cells was carried out by changes of medium every 3 days and through the passages from P0-P6.

14 culture flasks (T-75) of MSCs from P4 were subjected to differentiation for endothelial cells and cardiomyocytes. The morphology of the resulting cardiomyocytes resembles an interesting phenotype registered by Toma et al. 2002 [18] that evaluates MSCs differentiation when implanted in the ventricular wall of the heart, exhibiting a distinctive sarcomeric organization. Both lineages showed phenotypic changes during the differentiation process (Figure 5). Since cell properties change frequently after every subculture, previous studies recommend differentiation in P4, which matches our experimental results, due to the greater capacity for cell proliferation in this passage, favorable for the tissue repair process. 

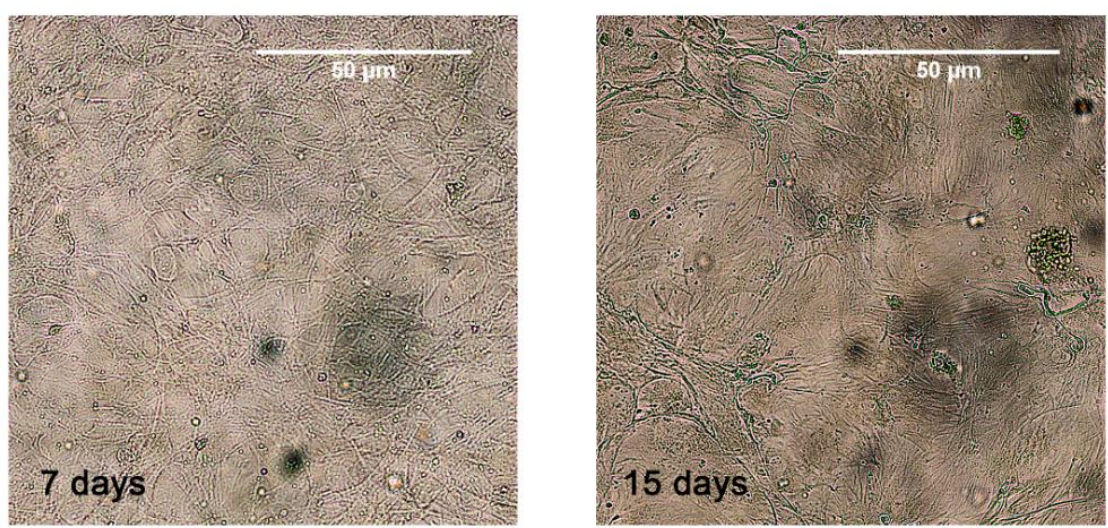

\section{Cardiomyocytes}
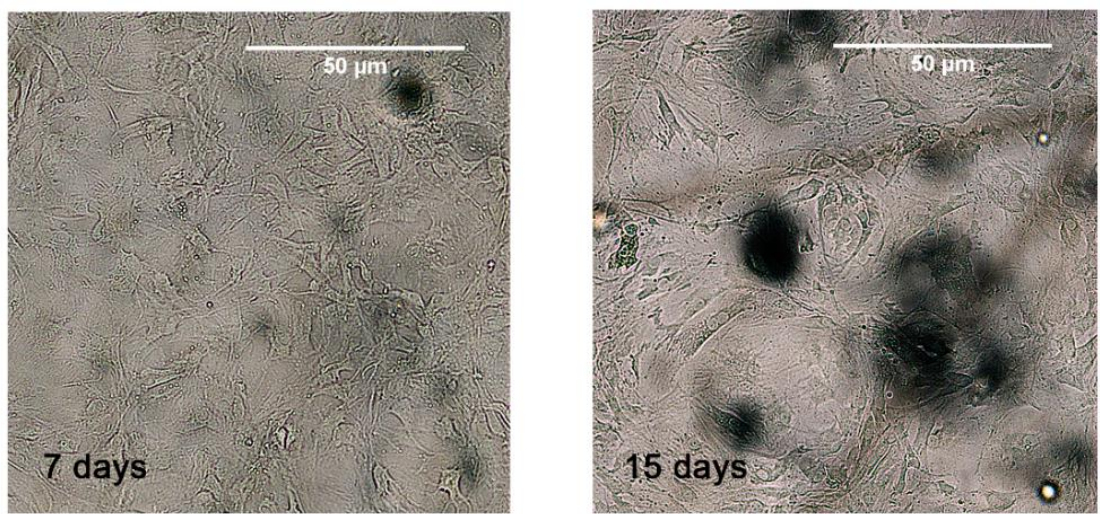

\section{Endothelial Cells}

Figure 5. MSC differentiation. Cells acquire the respective phenotype after 15 days in differentiation medium.

\subsection{Cell Seeding}

For the manufacturing of the $10 \times 10 \mathrm{~mm}$ scaffolds, 36 pieces were designed and printed by additive manufacturing in PETG CF on the Hyrel System 30M 3D printer (Heads MK-1, SDS-5, and SDS-10). The material did not deform significantly after sterilization and was externally fixed to a coverslip. Also, $300 \mu \mathrm{L}$ of cell suspension was poured into each compartment of the PETG CF piece and labeled according to the corresponding group and test.

\subsection{Cell Viability}

Cell viability assessment by trypan blue allowed to establish that seeded cells in the scaffolds preserve viability during in vitro culture for up to 28 days. Cell viability percentage remained above $80 \%$. For the group 1 scaffolds $(750$ cells $/ \mu \mathrm{L})$, living cells exhibited an average viability percentage of $98.23 \pm 3.35$ and for group $2(5000$ cells $/ \mu \mathrm{L})$ an average of $98.38 \pm 1.95$ (Figure 6). Odd value for day 12 in group 1 may be attributed to contamination in the measured scaffold. The scaffolds maintain cell viability during the different days of culture, which suggests the collagen matrix not only provides support to the cells, but also allows the transport of nutrients and gases to the cell and from it.

\subsection{Cell Migration}

Positive cells for DAPI, DiI and DiO were identified in the scaffolds of groups 3 and 4 (homogeneous distribution and crosswise distribution, respectively). During the evaluation period, the morphology of the cells was mostly oval, which was an indication of the static state of the cells (Figures 7 and 8 ). Although MSCs move slowly (cellular speed $<1 \mu \mathrm{m} / \mathrm{min}$ ), they usually exhibit multiple competing 
projections (lamellipodia and filopodia) when they are adhered and migrating, contrary to this the cells presented an appearance similar to their state in suspension.

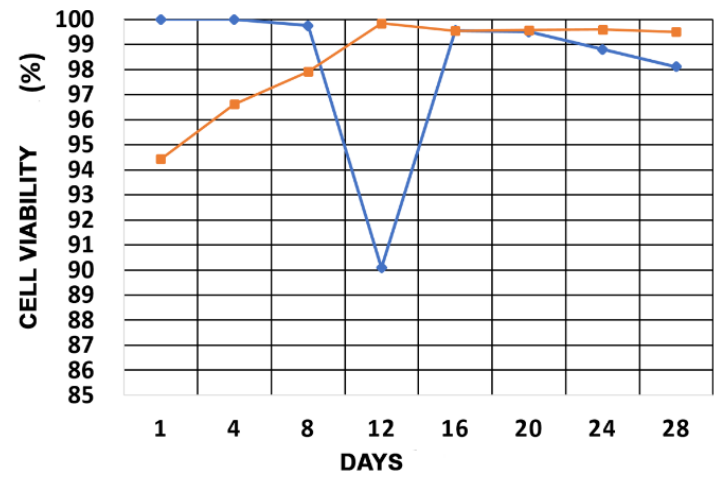

$\rightarrow$ Group 1 Viability - - Group 2 Viability

(a)

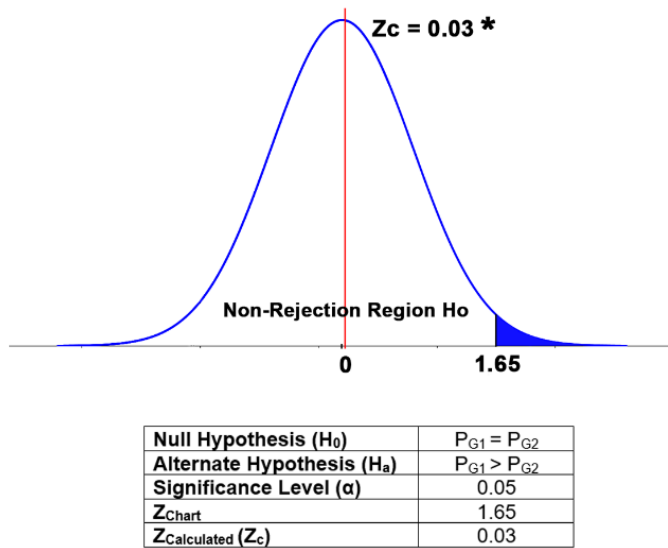

(b)

Figure 6. Cell viability. (a) Percentages of cell viability per group in a period of 28 days. $(\mathbf{b}) * p>0.05$. The hypothesis test for proportions was applied. $p<0.05$ represents the rejection of the null hypothesis. $p>0.05$ represents the non-rejection of the null hypothesis.

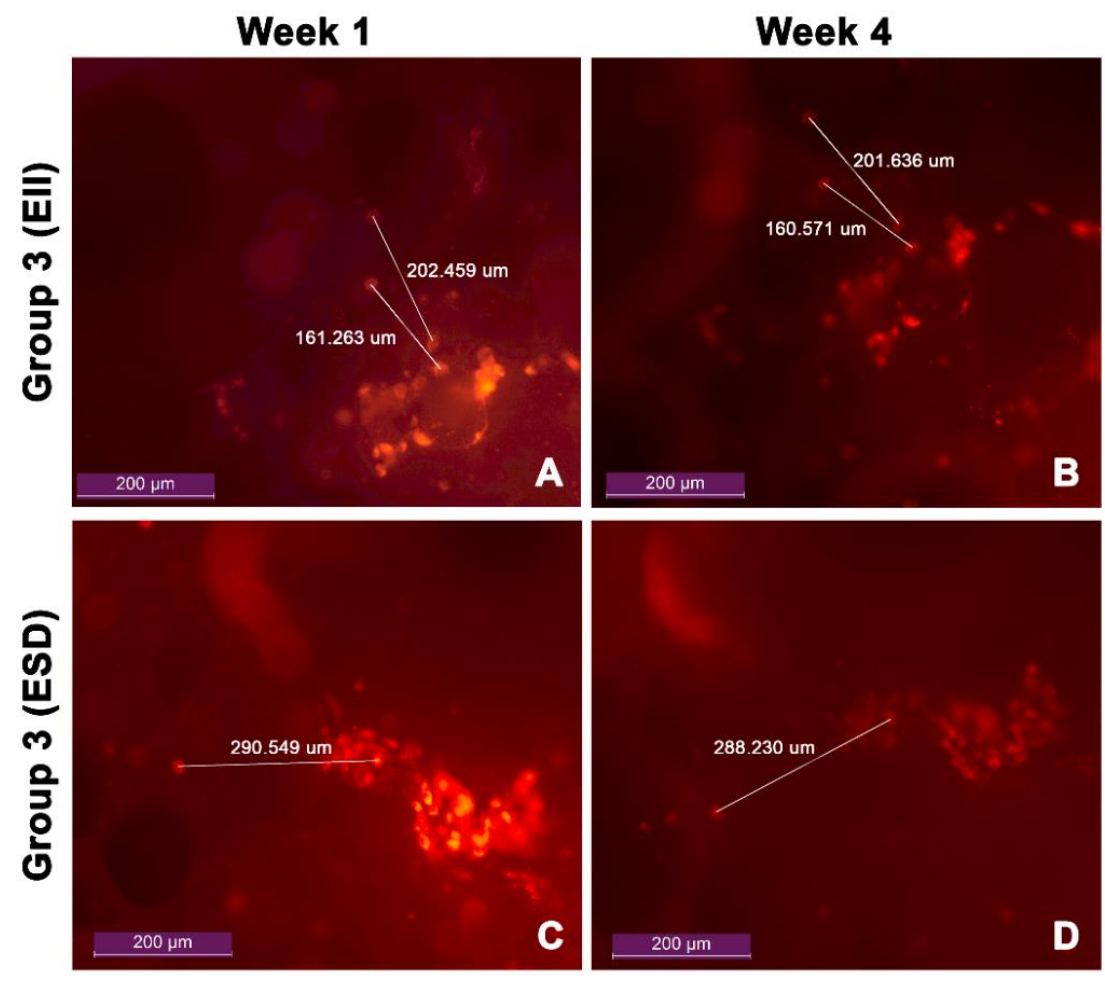

Figure 7. Cell images of homogeneous distribution scaffold monitored for 4 weeks. (EII): Lower Left Corner of scaffold. (ESD): Upper Right Corner of scaffold. (A) Cells position in lower left corner of scaffold, 1 week after seeding. (B) Cells position in lower left corner of scaffold, 4 weeks after seeding. No significant changes observed. (C) Cells position in upper right corner of scaffold, 1 week after seeding. (D) Cells position in upper right corner, 4 weeks after seeding. No significant changes observed. 

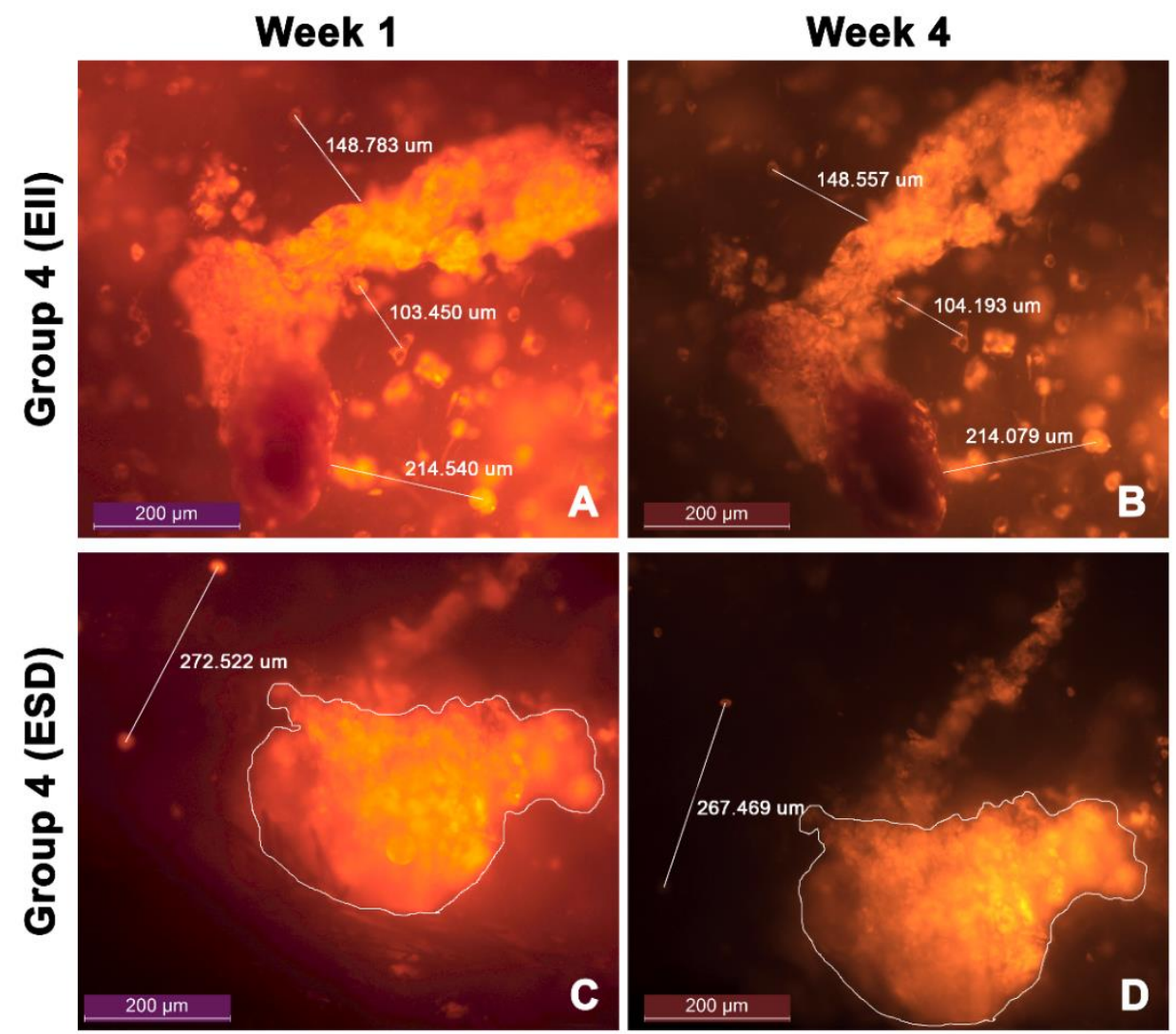

Figure 8. Cell images of crosswise distribution scaffold monitored for 4 weeks. (EII): Lower Left Corner of scaffold. (ESD): Upper Right Corner of scaffold. (A) Cells position in lower left corner of scaffold, 1 week after seeding. (B) Cells position in lower left corner of scaffold, 4 weeks after seeding. No significant changes observed. (C) Cells position in upper right corner of scaffold, 1 week after seeding. (D) Cells position in upper right corner, 4 weeks after seeding. No significant changes observed.

Cell reference points were located at different areas in the scaffold to monitor migration at regular intervals. Through the Image J digital image processing software, the distances between the same reference points were measured during the 4 weeks and similar values were found that did not represent a significant variation. The coefficient of variation of all the distances was less than $1 \%$ (Table 3), indicating a high precision, that is, a high degree in which the repetition of the measurement in different periods of time shows the same results. Therefore, no migration was recorded in any of the scaffold-cell types. However, previous studies such as that of Yu et al. 2012 [22], in which the analysis of MSCs in a mixed PCL-collagen scaffold found that more than $50 \%$ of the cells easily penetrated through the PCL macro-channel, however, cells contained within the collagen gels were retained on the scaffolds. Even so, the study emphasizes that cell viability doubled with the use of collagen gels.

Table 3. Cell migration distances in groups 3 and 4 .

\begin{tabular}{ccc}
\hline & Average Distance $(\mu \mathrm{m})$ & Coefficient of Variation \\
\hline \multirow{2}{*}{ Group 3 (EII) } & $160.92 \pm 0.48$ & $0.30 \%$ \\
& $202.05 \pm 0.58$ & $0.29 \%$ \\
\hline Group 3 (ESD) & $289.39 \pm 0.58$ & $0.57 \%$ \\
\hline \multirow{2}{*}{ Group 4 (EII) } & $103.48 \pm 0.54$ & $0.52 \%$ \\
& $149.01 \pm 1.38$ & $0.92 \%$ \\
\hline Group 4 (ESD) & $214.56 \pm 1.30$ & $0.61 \%$ \\
\hline
\end{tabular}




\subsection{Agent-Based Modeling of Cells in A Scaffold Implanted on the Infarcted Myocardium}

The effect of the MSCs over the tissue is the most observable in the graphics simulation (Figure 9). As mentioned before, MSCs exert an anti-inflammatory effect over the infarcted myocardium; thus, when the value of "inflammation" of a tissue agent decreases, its color in the simulation also changes to make the anti-inflammatory effect of MSCs along time visible. The color turns to a darker shade in order to make it look healthier, namely, more similar to the color of the tissue agents that are not part of the circular damaged area.

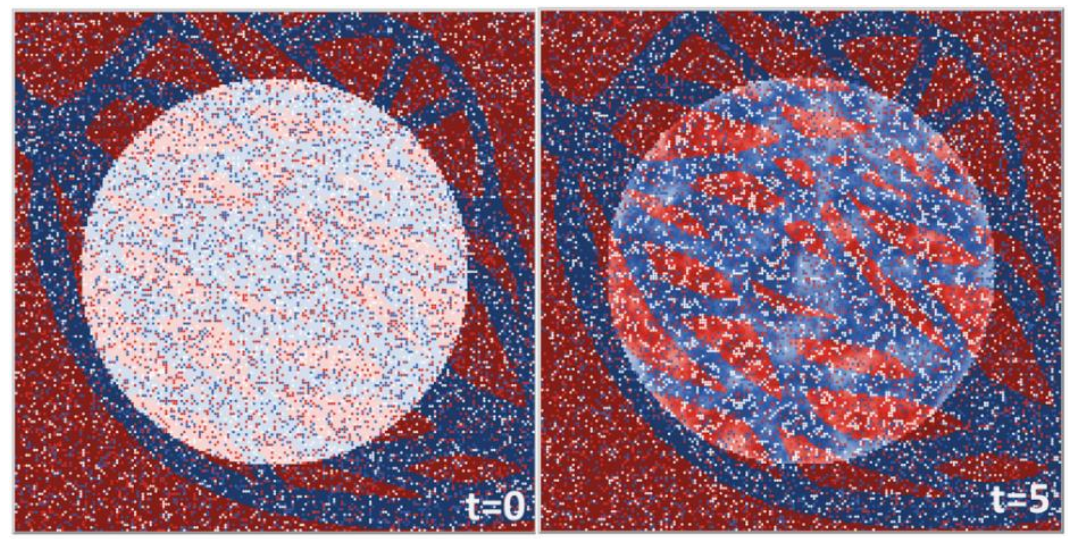

Figure 9. Example of the anti-inflammatory effect of MSCs after 5 days. In $t=0$ the damaged area is inflamed, thus its color is lighter than the rest of the tissue, while in $t=5$ the MSCs have exerted their anti-inflammatory effect, making the tissue look darker (healthier).

The described effect of the MSCs over the mean inflammation in the tissue caused its exponential decay during the simulations performed. An example of this observed result is shown in Figure 10 which resulted from a simulation that was initialized with 2500 cells of each type distributed homogenously, a scar size of 70\%, maximum 3 cells per position, "min-pc-cardio" 0.1, "max-pc-cardio" 0.8, "min-pc-endo" 0.05 and "max-pc-endo" 0.4 .

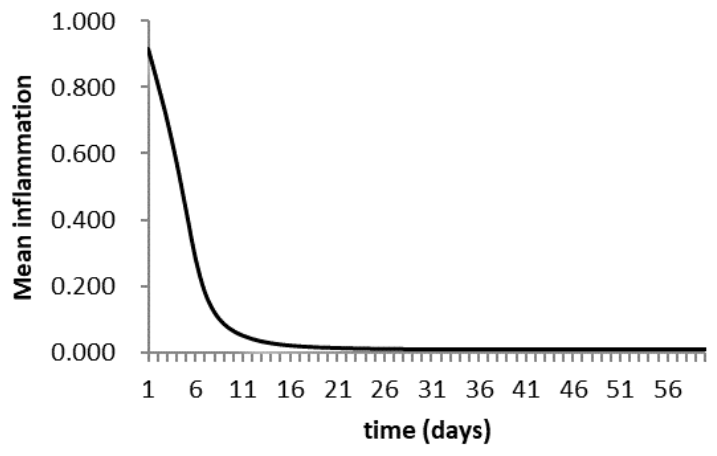

Figure 10. Mean inflammation of the simulated tissue along time.

The simulations performed with the model were implemented without a graphic interface since it would decrease the memory usage and shorten the execution time. SSH connection was used to run the experiments on a server with high RAM capacity (50 GB) since it allowed reducing the simulation time by $83 \%$ with respect to a desktop computer (8GB RAM).

Figure 11 shows the result of a simulation initialized with 75,000 cells of each type, the other initialization parameters are the same that were used for simulation in Figure 10, and the background image used to copy the blood vessels' pattern was changed. Likewise, a "cross" distribution pattern was evaluated, where endothelial cells were placed along a cross in the middle of the simulated area 
only, to visualize the differences that a cell pattern might have over the tissue. The same initialization parameters were used, and the resulting initial and final states are shown in Figure 12.
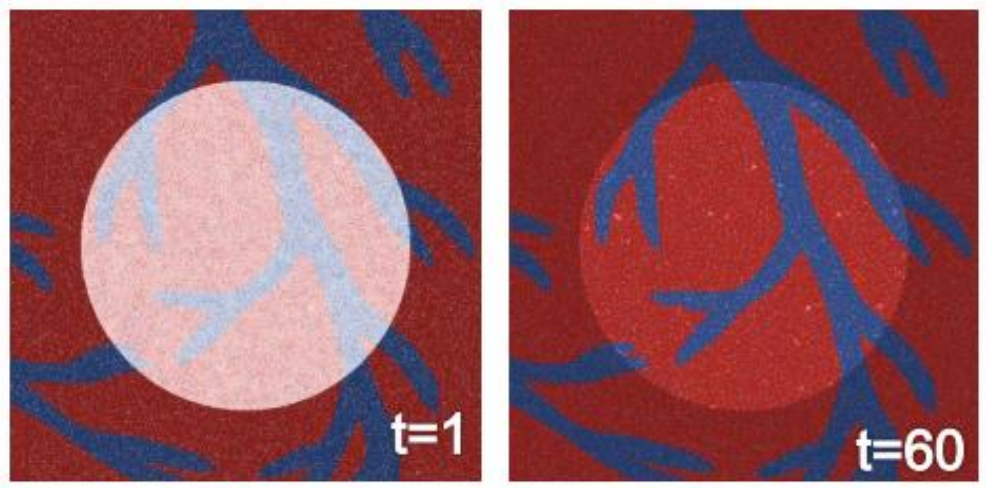

Figure 11. Output image of the initial and final state of the simulated area.
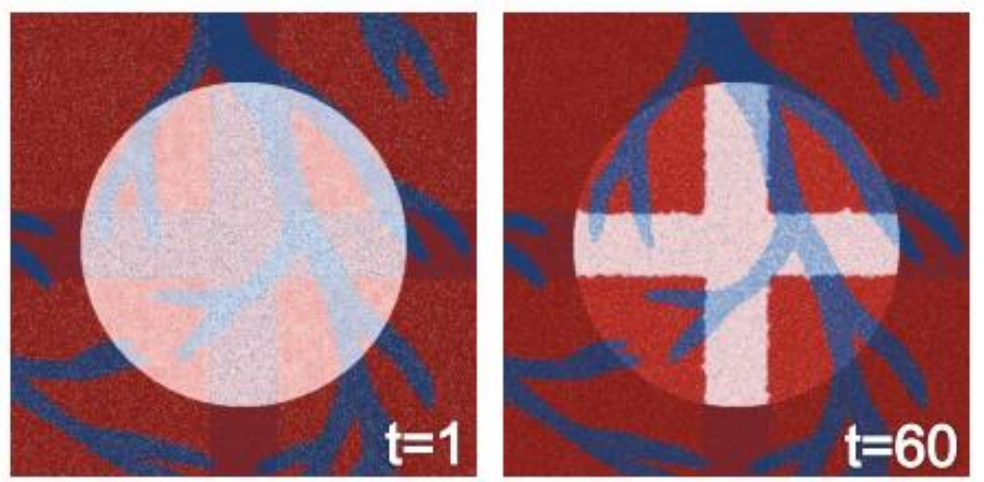

Figure 12. Output image of the initial and final state of the simulated area with a "cross" distribution of endothelial cells.

What can be observed from the latter is that when endothelial cells are put in a pattern, the absence of MSCs along the whole damaged tissue affects the reduction of inflammation in those areas where only endothelial cells are placed. This can be seen when the mean inflammation of both cases along time is plotted, as in Figure 13, where the results of a few simulations for inflammation are compared. There we can observe how the mean inflammation after 60 days is clearly affected by the distribution of MSCs along the infarcted tissue, thus the model might be a useful tool for testing hypothesis on the distribution of cells along the biodevices.

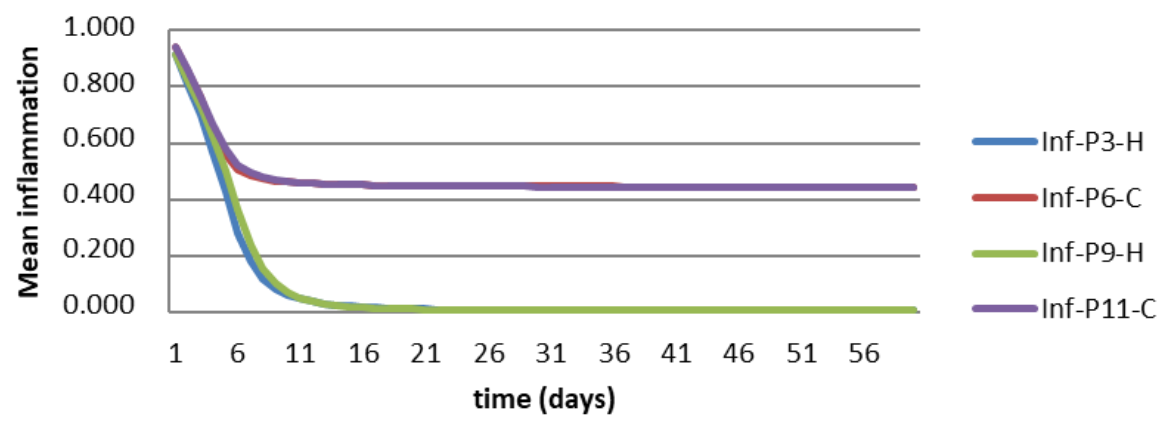

Figure 13. Mean inflammation along time (for a model initialized with a concentration of 75000, and two different distributions of endothelial cells in the scaffold). 
The model can also output results about the population size of each cell type along time. This is shown in Figure 14, a plot that shows the cell counts of a population, initialized with 25,000 cells of each type and the same parameters used before, over time, for a simulation of 60 days. It is observed that the MSCs population increases during the first days, which agrees with the high inflammation that needs to be controlled during the first days, and then it starts decreasing suggesting that the cells were following differentiation processes, which cause the growth of the other two cell types' populations.

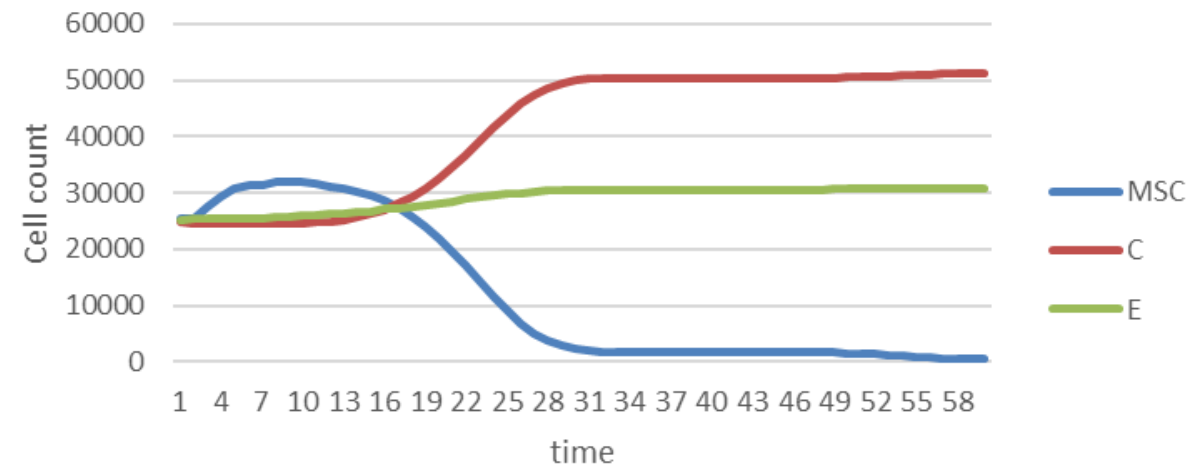

Figure 14. Cell population's behavior along time (days).

The model developed here, which was used to elaborate this section, can be found in the link provided as Supplementary Material.

\section{Discussion}

\subsection{In Vitro Experimentation}

Regarding tissue engineering, we are still beginning to understand the processes that lead to the formation of an integrated tissue, such as adhesion, migration and cellular differentiation. Achieving the complete implantation of cellular constructs in vivo requires not only examining a complex network of biological factors, based on in vitro studies, but also modeling cell behavior to assess the engineered scaffold.

In the extracellular matrix, MSCs play a fundamental role in the secretion of proteins and carbohydrates, in the organization of the structure of the matrix, and in the activation of the repair process by infiltrating the damaged tissue. Given the immunomodulatory properties of MSCs, they have become attractive candidates for the treatment of fibrosis. However, the specific mechanisms of migration and proliferation, as well as their anti-inflammatory and angiogenic properties, remain poorly understood [23].

The present work achieved isolation of rat bone marrow stem cells, the construction of collagen scaffolds with undifferentiated and differentiated MSCs, and the observation of cell viability and migration assessment.

During cell isolation and culture, it was observed an important relationship between the age of the animal (4 weeks) and the increase in the cell proliferation rate, obtaining a high confluence $(80-90 \%)$ after $96 \mathrm{~h}$. The ability of differentiation of these cells towards the endothelial and cardiomyocyte lineage, carried out in P4, was proven by finding a greater capacity for cell proliferation in this subculture.

When evaluating the changes in cell viability of the scaffold, both cell concentrations (750 and 5000 cells $/ \mu \mathrm{L})$ were found to have high viability percentages over time $(98.23 \pm 3.35$ and $98.38 \pm 1.95$ respectively) with a negligible variance difference. Although cell concentration does not affect cell survival in the study scaffolds, it is important to consider that a low concentration of cells can decrease the rate of cellular proliferation in the scaffold, as well as the effectiveness of it, once it has been implanted, to generate cellular responses and paracrine effects fundamental for the repair of damaged 
tissue. On the other hand, a high concentration of cells can cause cell death due to the limitation of the transport of nutrients and oxygen, the accumulation of metabolic byproducts, and high osmolarity [24].

The high percentage of cell viability obtained suggested that scaffold gelation with the ammonium hydroxide vapor chamber did not affect cell survival. This factor was determinant in the manufacturing process of the construct, since the cell suspension required gelation to simulate the properties of the extracellular matrix. In the same way, it was corroborated that both type I collagen and PETG CF material preserve cell life, which is beneficial for future studies that may include these materials in a tissue printing technique.

Regarding the evaluation of cell mobility in the scaffold, it was found in this study that differentiated and undifferentiated MSCs from groups with different distributions remained static in the collagen gel for a period of 4 weeks. They did not exhibit the characteristic morphology of their migration, on the contrary, they retained the rounded shape they have when in suspension.

From the results obtained in this study, for the manufacture of scaffolds of in vivo tests, it is proposed first of all that the cellular concentration (according to the size of the construct) remains between the range of $750-5000$ cells $/ \mu \mathrm{L}$, since it does not affect cell survival. As for cell migration, it is known that the cells in an aggregate initially migrate in a random manner so that they leave regions of insufficient adhesion and find areas of strong adhesion, this could indicate that the cells of the scaffolds did not form mature focal adhesions, which results in the absence of significant tensile forces. This would explain why microscopy images show little evidence of cell movement. It is proposed to improve cell adhesion by increasing the proportion of SFB in the culture medium of cellular constructs or functionalize the scaffolds with fibronectin. It is possible to preserve type I collagen as the polymer for planting the cells, since it simulates the natural microenvironment of the same and does not affect cell viability, and this type of fibrillar collagen interacts with the cells through integrin receptors on the cell surface. On the other hand, manufactured scaffolds do not disintegrate upon contact with a liquid medium, so they do not require the combination with other materials to be transported and implanted.

Although there was no difference in the effect of cell distribution on cell migration, it is important to consider that, in aggregates composed of several cell populations, these are rearranged according to the density of cadherin on the surface, that is, cells with more cadherin are located inside the aggregate, while cells with less are located in the periphery.

According to a study conducted by Portalska et al. 2012 [25], the migration velocity of differentiated MSCs to endothelial cells is higher than the velocity of undifferentiated MSCs in the repair of damaged tissue, which is simulated in the model by allowing endothelial cells to move a bigger number of "steps" each simulated day. Therefore, it is convenient to evaluate the crosswise distribution, proposed in this work, in in vivo studies and in the model, since separating the endothelial cells could mean a more efficient migration and therefore a rapid vascularization of the graft for the sustenance of the implanted cells.

\subsection{Agent-Based Modeling}

The results obtained from the in vitro experiments contributed to establishing the values of some parameters in an agent-based model in order to simulate some of the processes that occur in the microenvironment of the scaffolds based on real observed behaviors.

Even when the in vitro experimentation did not show significant cell migration, it is still included in the computational model, where cell migration is not only random but also affected by the surrounding tissue characteristics, since cell behavior in the scaffolds can change within a non-isotropic or in vivo environment; because cell migration is strongly related to the secretion of activation factors and the expression or organization of molecules of the extracellular matrix [26]. One example of the last is the angiogenesis process, which also can be tested with the agent-based model by using a black and white image to load a pattern for the arrangement of endothelial cells, and observing their migration through each day, not only following random steps but also orientating themselves to connect the new tissue with the already existent blood vessels, which would be the simulation of a vascularization process. 
Further experimentation with the model developed could help determine the effect of the concentration of cells once they are implanted, as it considers the inflammation as a factor that inversely affects the proliferation and checks for enough space available before dividing and simulates the activation of myocyte proliferation that is induced by MSCs [12].

Regarding the process of developing the model, it is important to outline that it was carried out at the same time that the cell cultures were being observed, which means that none of the information that was obtained from the in vitro observations was available and neither were the conclusions that this observation drew. Thus, the model was developed as a general model that would contain known types of agents and simulate some interactions between those agents. Some of these interactions were modeled based on available research and empirical knowledge, but the values of some parameters were still unknown and some interactions and characteristics that could affect the cell behavior in vivo were not included until later.

Modelling differentiation, apoptosis, proliferation and migration makes the results qualitatively comparable to the actual behavior that cells would have on the infarcted myocardium [10], as these processes occur naturally at a cellular level [19] and it is expected from them to have an effect on the infarcted myocardium [10] after implanting the proposed scaffold.

The above leads us to conclude that an agent-based model allows the progressive addition of new information in a somehow simple way, and that it will permit the modification of some parameters or actions for them to meet real observed cell-level behaviors and interactions. A further analysis of the results of the simulation of the cellular behavior in the infarcted myocardium, followed with an in vivo experimentation, for validation, would be key to determine the accuracy of the model; however, as it is based on what is reported by different authors about MSCs behavior, it is already seen as a good tool to aid the engineering of a scaffold for myocardial tissue regeneration after infarction, since it might be a helpful tool for testing hypothesis about the characteristics of the scaffold and maybe reduce the amount of in vivo experimentation needed to formulate future treatments.

Even though the agent-based modeling technique is seen as an appropriate tool for modeling cell behavior, it is important to mention that it has also some disadvantages. One of them is the high use of RAM memory, which depends directly on the number of agents simulated, and the fact that is not so easy to parallelize the simulation, which means that for a large number of agents, a large processing capacity is required in order to reduce the time necessary to run a simulation.

\section{Conclusions}

Assessment of cell behavior in vitro and in silico represents a substantial strategy in scaffold engineering. The evaluation of essential cell interactions and properties within a construct, such as cell viability, differentiation, proliferation, migration, inflammation reduction and spatial composition might conduce to the enhancement in the design of myocardial regeneration scaffolds.

In vitro testing resulted in high cell viability regardless of cell concentration in the scaffold, the gelation method with ammonium hydroxide, the use of PETG CF in 3D printing or the integration to type I collagen; none of these factors affected the survival of the cell types. Cells did not exhibit migration in the collagen scaffolds, which might suggest they did not generate significant tensile forces to create focal adhesions.

It is suggested that the most convenient design contains an average cell concentration between the range evaluated in this study, and that the model could help in determining the effect of this and other concentrations when used as a treatment for the infarcted myocardium. Seeding in collagen gel type I, as a polymer that fulfills the extracellular matrix function, and a crosswise distribution of endothelial cells are also seen as favorable features for the scaffold. However, as only one distribution was evaluated, and the cellular environment was controlled in vitro, it is possible to find a different distribution that could aid endothelial cells to perform angiogenesis.

The agent-based approach used to build the described model was correct, as it allows the evaluation of the interactions between the cells and their environment (both seen as agents) and has 
provided a tool that allows testing hypotheses like the ones suggested previously, without specifically modeling the complex behavior that underlies a system conformed by so many agents.

It is imperative to consider other factors such as porosity, which plays a role in providing surface area for cell attachment, and the idea that paracrine factors can be induced to the scaffolds to improve their bioactivity. An ideal scaffold is the outcome of a balance between all these factors.

Supplementary Materials: The following are available online at https://github.com/victoriarl/MSCmodelDATA/tree/master/Netlogo-model, Figure S1: Netlogo-model.nlogo, Netlogo file S2: capillars.png, image S3: channels.png, image S4: cross.png, image.

Author Contributions: Conceptualization, D.V.R.L., M.I.M.E., C.A.P.-R., A.J.R.A. and P.A.N.A.; Data curation, C.A.P.-R., A.J.R.A. and P.A.N.A.; Formal analysis, D.V.R.L., M.I.M.E., C.A.P.-R., A.J.R.A. and P.A.N.A.; Funding acquisition, P.A.N.A.; Investigation, D.V.R.L. and M.I.M.E.; Methodology, D.V.R.L., M.I.M.E., C.A.P.-R., A.J.R.A. and P.A.N.A.; Project administration, A.J.R.A. and P.A.N.A.; Resources, C.A.P.-R. and P.A.N.A.; Software, D.V.R.L., C.A.P.-R. and Álvaro J. Rojas Arciniegas; Supervision, C.A.P.-R., A.J.R.A. and P.A.N.A.; Validation, C.A.P.-R., A.J.R.A. and P.A.N.A.; Visualization, D.V.R.L. and M.I.M.E.; Writing-original draft, D.V.R.L. and M.I.M.E.; Writing-review \& editing, C.A.P.-R. and A.J.R.A.

Funding: This research was partially funded by the Sistema General de Regalías of Valle del Cauca, as it was comprised in the development of the project titled "Research and Production of Tissues, Organs and Biodevices for use in Regenerative Medicine, Cali, Valle del Cauca", developed by the universities of Autónoma de Occidente, Universidad del Valle and Hospital Universitario del Valle (HUV).

Conflicts of Interest: The authors declare no conflict of interest.

\section{References}

1. Malliaras, K.; Marbán, E. Cardiac cell therapy: Where we've been, where we are, and where we should be headed. Br. Med Bull. 2011, 98, 161-185. [CrossRef]

2. Chan, B.P.; Leong, K.W. Scaffolding in tissue engineering: General approaches and tissue-specific considerations. Eur. spine J. 2018, 17 (Suppl. 4), 467-479. [CrossRef]

3. Domenech, M.; Polo-Corrales, L.; Ramirez-Vick, J.E.; Freytes, D.O. Tissue Engineering Strategies for Myocardial Regeneration: Acellular Versus Cellular Scaffolds? Tissue Eng. Part B Rev. 2016, 22, 438-458. [CrossRef] [PubMed]

4. Bitar, K.N.; Zakhem, E. Design strategies of biodegradable scaffolds for tissue regeneration. Biomed. Eng. Comput. Biol. 2014, 6, 13-20. [CrossRef] [PubMed]

5. Brodland, G.W. How computational models can help unlock biological systems. Semin. Cell Dev. Biol. 2015, 47-48, 62-73. [CrossRef]

6. Briers, D.; Haghighi, I.; White, D.; Kemp, M.L.; Belta, C. Pattern synthesis in a 3D agent-based model of stem cell differentiation. In Proceedings of the 2016 IEEE 55th Conference on Decision and Control (CDC), Las Vegas, NV, USA, 12-14 December 2016.

7. Tanaka, N.; Yamashita, T.; Sato, A.; Vogel, V.; Tanaka, Y. Simple agarose micro-confinement array and machine-learning-based classification for analyzing the patterned differentiation of mesenchymal stem cells. PLoS ONE 2017, 12, 1-17. [CrossRef] [PubMed]

8. Inverno, M.; Saunders, R. Agent-Based Modelling of Stem Cell Self-organisation in a Niche. Engineering Self-Organising Systems: Methodologies and Applications; Springer: Berlin, Germany, 2005; pp. 52-68.

9. Garzoni, L.R.; Rossi, M.I.D.; de Barros, A.P.D.N. Dissecting coronary angiogenesis: 3D co-culture of cardiomyocytes with endothelial or mesenchymal cells. Exp. Cell Res. 2009, 315, 3406-3418. [CrossRef] [PubMed]

10. Ramirez Lopez, D.V.; Pena-Reyes, C.; Rojas, A.J. Agent-based modeling of mesenchymal stem cells on a 3D-printed bio-device for the regenerative treatment of the infarcted myocardium. In Proceedings of the 2018 IEEE International Conference on Bioinformatics and Biomedicine (BIBM), Madrid, Spain, 3-6 December 2018; pp. 2033-2040.

11. Wilensky, U. What is NetLogo? The NetLogo 6.0.2 User Manual; Northwestern University: Evanston, IL, USA, 1999.

12. Hatzistergos, K.E.; Quevedo, H.; Oskouei, B.N.; Hu, Q.; Feigenbaum, G.S.; Margitich, I.S.; Mazhari, R.; Boyle, A.J.; Zambrano, J.P.; Rodriguez, J.E.; et al. Bone Marrow Mesenchymal Stem Cells Stimulate Cardiac Stem Cell Proliferation and Differentiation. Circulation Res. 2010, 107, 913-922. [CrossRef] [PubMed] 
13. Frangogiannis, N.G.; Smith, C.W.; Entman, M.L. The inflammatory response in myocardial infarction. Cardiovasc. Res. 2002, 53, 31-47. [CrossRef]

14. Świątkiewicz, I.; Koziński, M.; Magielski, P. Course of inflammatory activation during acute myocardial infarction in patients with preserved left ventricular systolic function. Folia Med. Copernic. 2014, 2, 6-18.

15. Martire, A.; Bedada, F.B.; Uchida, S. Mesenchymal stem cells attenuate inflammatory processes in the heart and lung via inhibition of TNF signaling. Basic Res. Cardiol. 2016, 111, 54. [CrossRef] [PubMed]

16. Cano, G.; García-Rodríguez, J.; Orts, S. Predicción de solubilidad de fármacos usando máquinas de soporte vectorial sobre unidades de procesamiento gráfico. Rev. Int. Methodos. Numer. Calc. Diseno. 2007, 33, 97-102. [CrossRef]

17. Tan, J.; et al. Ablation of TNF- $\alpha$ receptors influences mesenchymal stem cell-mediated cardiac protection against ischemia. Shock 2010, 3, 236-242. [CrossRef] [PubMed]

18. Høyem, M.R.; Måløy, F.; Jakobsen, P.; Brandsdal, B.O. Stem cell regulation: Implications when differentiated cells regulate symmetric stem cell division. J. Theor. Biol. 2015, 380, 203-219. [CrossRef] [PubMed]

19. Thrivikraman, G.; Boda, S.K.; Basu, B. Unraveling the mechanistic effects of electric field stimulation towards directing stem cell fate and function: A tissue engineering perspective. Biomaterials 2018, 150, 60-86. [CrossRef]

20. Garijo, N.; Manzano, R.; Osta, R.; Perez, M.A. Stochastic cellular automata model of cell migration, proliferation and differentiation: Validation with in vitro cultures of muscle satellite cells. J. Theor. Biol. 2012, 314, 1-9. [CrossRef]

21. Toma, C.; Pittenger, M.F.; Cahill, K.S.; Byrne, B.J.; Kessler, P.D. Human mesenchymal stem cells differentiate to a cardiomyocyte phenotype in the adult murine heart. Circulation 2002, 105, 93-98. [CrossRef]

22. Yu, H.-S.; Won, J.-E.; Jin, G.-Z.; Kim, H.-W. Construction of mesenchymal stem cell-containing collagen gel with a macrochanneled polycaprolactone scaffold and the flow perfusion culturing for bone tissue engineering. Biores. Open Access 2012, 1, 124-136. [CrossRef]

23. Spees, J.L.; Lee, R.H.; Gregory, C.A. Mechanisms of mesenchymal stem/stromal cell function. Stem cell Res. Ther. 2016, 7, 125. [CrossRef] [PubMed]

24. Krampe, B.; Al-Rubeai, M. Cell death in mammalian cell culture: Molecular mechanisms and cell line engineering strategies. Cytotechnology 2010, 62, 175-188. [CrossRef]

25. Janeczek Portalska, K.; Leferink, A.; Groen, N. Endothelial Differentiation of Mesenchymal Stromal Cells. PLoS ONE 2012, 7, e46842. [CrossRef] [PubMed]

26. Bear, J.E.; Haugh, J.M. Directed migration of mesenchymal cells: Where signaling and the cytoskeleton meet. Curr Opin. Cell Biol. 2014, 30, 74-82. [CrossRef] [PubMed] 